\title{
Argon Triple-Point Device for Calibration of SPRTs
}

\author{
B. Kołodziej • H. Manuszkiewicz • \\ A. Szmyrka-Grzebyk - L. Lipiński • A. Kowal • \\ P. P. M. Steur - F. Pavese
}

Received: 9 August 2013 / Accepted: 15 October 2014 / Published online: 30 October 2014

(C) The Author(s) 2014. This article is published with open access at Springerlink.com

\begin{abstract}
This paper presents an apparatus for the calibration of long-stem platinum resistance thermometers at the argon triple point $\left(T_{90}=83.8058 \mathrm{~K}\right)$, designed at the Institute of Low Temperature and Structural Research, Poland (INTiBS). A hermetically sealed cell filled at the Istituto Nazionale di Ricerca Metrologica, Italy with high purity gas $(6 \mathrm{~N})$ is the main element of this apparatus. The cell is placed in a cryostat fully immersed in liquid nitrogen. A temperature-controlled shield ensures the quasi-adiabatic condition needed for proper realization of the phase transition. A system for correcting the temperature distribution along the thermometer well is also implemented. The cell cooling and argon solidification is carried out by filling the thermometer well with liquid nitrogen. A LabVIEW computer program written at INTiBS automatically controls the triple-point realization process. The duration of a melting plateau in the apparatus lasts for about $24 \mathrm{~h}$. The melting width for $F$ between $20 \%$ and $80 \%$ was $<0.3 \mathrm{mK}$. The reproducibility of the plateau temperature is better than $\pm 20 \mu \mathrm{K}$.
\end{abstract}

Keywords Argon triple point - Platinum thermometer - Temperature scale

\section{Introduction}

The triple point of argon is one of the low-temperature fixed points of the International Temperature Scale of 1990, ITS $90\left(T_{90}=83.8058 \mathrm{~K}\right)$ needed for the calibration of

B. Kołodziej $(\bowtie) \cdot$ H. Manuszkiewicz · A. Szmyrka-Grzebyk · L. Lipiński · A. Kowal · F. Pavese Instytut Niskich Temperatur i Badań Strukturalnych PAN, Okólna 2, 50-422 Wrocław, Poland e-mail: b.kolodziej@int.pan.wroc.pl

P. P. M. Steur · F. Pavese

Istituto Nazionale di Ricerca Metrologica, Strada delle Cacce 73-91, 10-135 Turin, Italy 
standard platinum resistance thermometers, with both long stem (SPRT) and capsule type (CSPRT). Several models of cryostat and systems for the calibration of SPRTs at the triple point of argon were built by different institutions [1-6] since more than thirty years. CSPRTs are calibrated in small sealed cells under good adiabatic conditions [7-10]. Because of the size of SPRTs, it is difficult to build a cryostat for its calibration in a similar way.

At the Institute of Low Temperature and Structure Research (INTiBS), Wroclaw, a new cryostat model for calibration of long-stem SPRTs at the argon triple point was built. Based on a long-term experience in work with sealed cells used for calibration of CSPRTs in the low-temperature range, the thermometric cell for the calibration of long-stem SPRTs was designed. The cell was made in cooperation with the Istituto Nazionale di Ricerca Metrologica (INRIM), Turin. The cell is placed in a vacuum chamber immersed in a liquid nitrogen bath allowing realization of the argon triple point and calibration of both types of standard platinum thermometers-long stem and capsule type in a quasi-adiabatic condition.

The characteristics of the system and the testing results are reported, showing that reproducible plateaux with the realized temperature spanning $<300 \mu \mathrm{K}$ can go on for several dozens of hours.

\section{Construction of the System}

\subsection{Argon Cell}

A sketch of the argon cell is shown in Fig. 1. The thermometric cell wall is made of stainless steel. The lower part of the cell outer diameter is $22 \mathrm{~mm}$ and has a length of $60 \mathrm{~mm}$, properly sized to the dimensions of the platinum sensor of the SPRTs. Inside that part of the cell, a heat exchanger made of a copper block is installed. At the bottom of the cell, a Teflon bracket supports the copper block in a stable position. The upper part of the thermometric cell is enlarged to a diameter of $60 \mathrm{~mm}$ in order to increase the cell volume for reducing gas (argon) pressure at room temperature below $6 \mathrm{MPa}$. The cell contains an accurately measured amount of about $0.35 \mathrm{~mol}$ of high-purity argon (6N, Messer GmbH, Germany). The impurities of the gas declared by the producer are as follows: oxygen, nitrogen, water vapor, hydrocarbons, and $\mathrm{CO} / \mathrm{CO}_{2}$, all below $0.5 \mathrm{vppm}$.

The mechanical part of the cell was made at INTIBS. It was filled at INRIM with the argon mentioned before and permanently sealed using an INRIM pinch-weld technique [11].

Through the central part of the cell, a stainless tube (thermometer well diameter of $8 \mathrm{~mm}$ ) passes up to a flange. In the lower part of the cell, a heater H1 is used for performing the melting with the heat pulse technique. The temperature of the cell is also monitored by a small thermometer PRT1.

\subsection{Cryostat}

The cryostat design is presented in Fig. 2. The argon cell surrounded by superinsulation and a copper thermal shield is located in the vacuum chamber (see Fig. 3). 


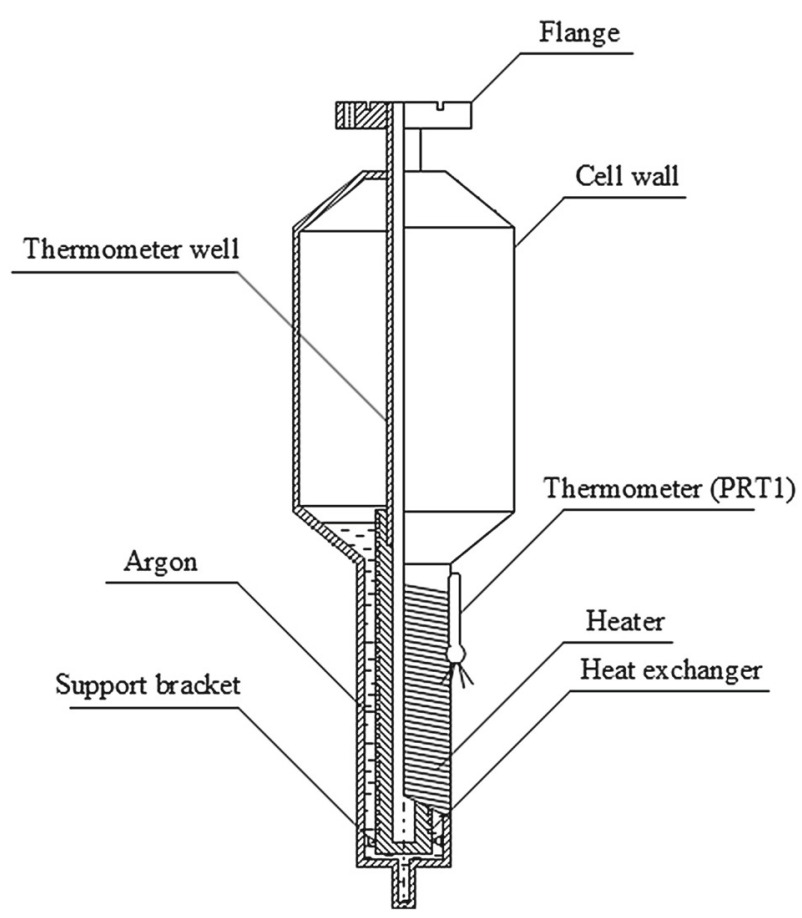

Fig. 1 Argon cell design

The chamber is sealed by an indium gasket and immersed in a liquid nitrogen Dewar (50L). A turbo-molecular vacuum system is used to maintain vacuum insulation at a pressure inside the chamber below $10^{-4} \mathrm{~Pa}$. For obtaining stable thermal conditions in the cryostat during the argon triple-point realization, the level of liquid nitrogen above the vacuum chamber is maintained constant (near $10 \mathrm{~cm}$ ). For this purpose, a device is used consisting of a plastic foam cup, a suspension cord, and a counterweight. The cryostat is immersed at a constant depth in liquid nitrogen, and its weight is balanced with buoyancy and with the weight of a counterweight. Measurements can be performed without refilling nitrogen for up to $12 \mathrm{~h}$.

To ensure sufficient thermal contact between the thermal shield and the liquid nitrogen outside the vacuum chamber, bronze springs, as shown in Fig. 4, are attached to the bottom of the shield. The springs ensure an initial cool-down of the shield in a reasonably short time. The temperature of the shield is then controlled with a PID (proportional-integral-derivative) controller. For this purpose, a heater $\mathrm{H} 2$ and a thermometer PRT2 are mounted on the shield. The cell cool-down and argon solidification are carried out by filling the thermometer well with liquid nitrogen. The SPRT thermometer is outside the well at this moment and the temperature of the cell is monitored by thermometer PRT1. The heater H1 mounted at the lower part of the cell allows increase in the cell temperature step-wise up to the argon triple point.

The upper part of the thermometric well is immersed in liquid nitrogen and has a lower temperature than the cell during the phase transition. This will probably cause a 


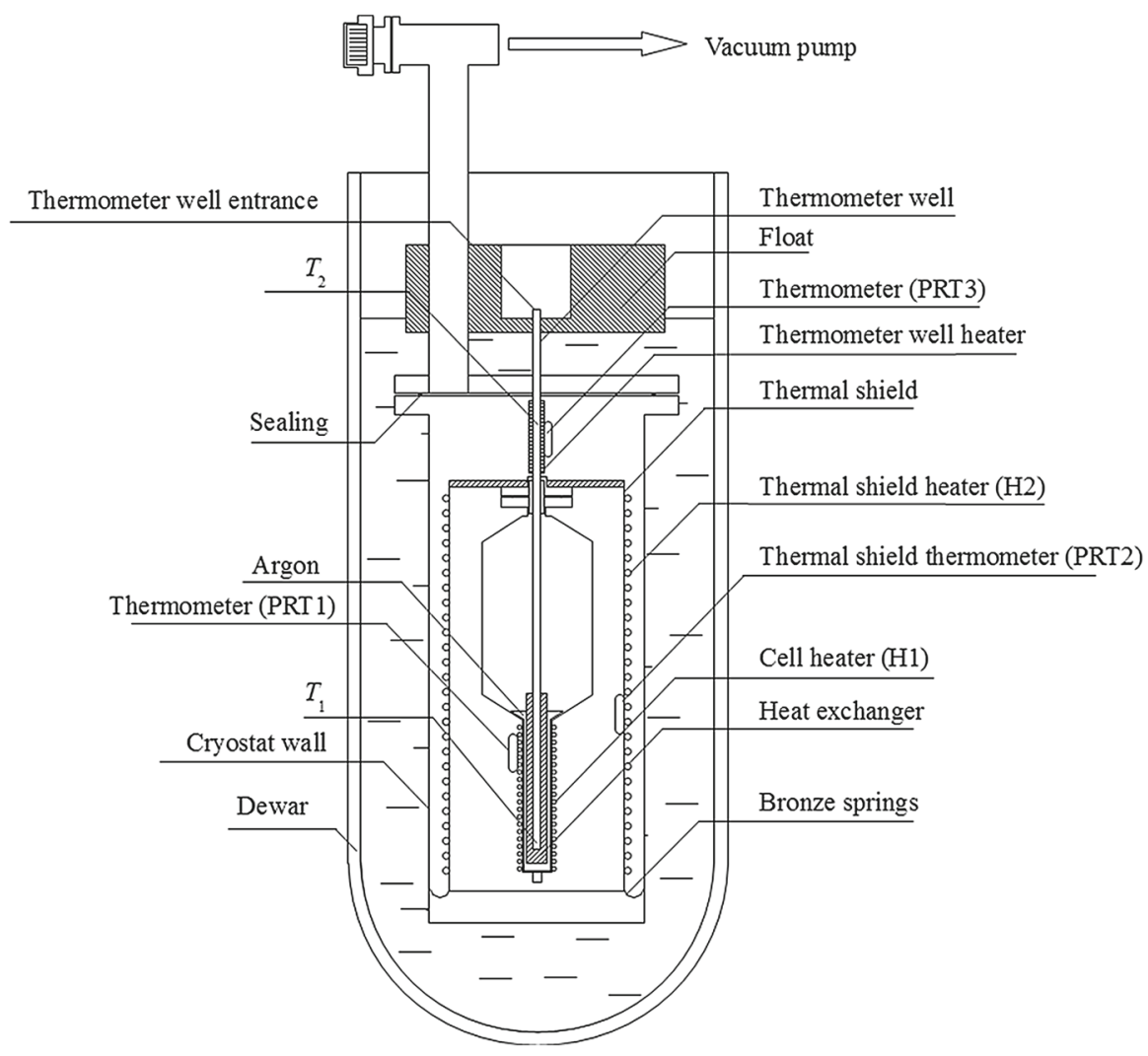

Fig. 2 Cryostat design

heat exchange by convection along the gap between the thermometer and the thermometric well wall, resulting in a reduction of the observed temperature of the triple point. A system for correcting the temperature distribution along the thermometer well was implemented. To reduce the disturbing effect of convection, the upper part of the well is heated by the heater $\mathrm{H} 3$ to the temperature $T_{2}$ monitored by thermometer PRT3 (see Fig. 2). The influence of the temperature of the upper part of the thermometer well $\left(T_{2}\right)$ on the observed phase transition temperature is shown in Fig. 5. The measurement was performed using a glass-sheath SPRT thermometer. A curve "a" was obtained when an aperture between SPRT and the thermometric well was large (approximately $1 \mathrm{~mm}$ in diameter). When the aperture width is decreased by filling it with the thin Teflon tape in the space close to the heater $\mathrm{H} 3$ along the thermometer sheath, the influence of temperature $T_{2}$ on the temperature of the cell is much lower (curve "b").

The thermal resistance $R_{\mathrm{S}}$ between the cell and the thermal shield was determined in an experiment consisting in the step change of the shield temperature and simultaneous measurement of changes in cell temperature drift. The cell temperature was below the argon triple-point temperature, and argon was totally solidified. $R_{\mathrm{S}}$ was calculated with 


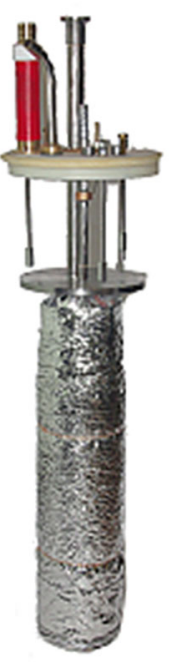

(a)

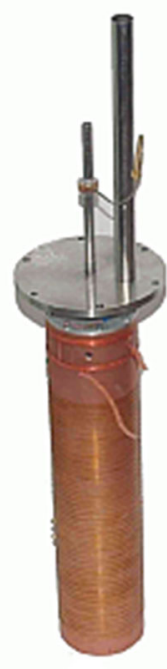

(b)

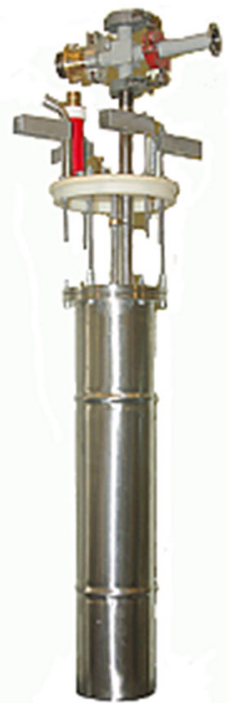

(c)

Fig. 3 Argon cell: (a) with super-insulation, (b) with thermal shield, and (c) vacuum housing

Fig. 4 Bronze springs for obtaining thermal contact between the shield and vacuum chamber

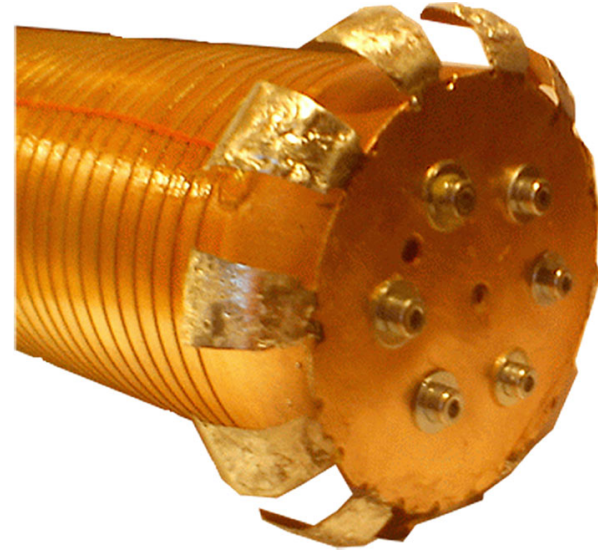

$$
R_{\mathrm{S}}=\frac{\Delta T_{\mathrm{E}}}{C \cdot \Delta(\mathrm{d} T / \mathrm{d} t)},
$$

where $\Delta T_{\mathrm{E}}$ is the temperature difference of the thermal shield before and after a step change, $C$ is the cell thermal capacity, and $\Delta(\mathrm{d} T / \mathrm{d} t)$ means the change of the cell temperature drift after thermal shield temperature modification. $R_{\mathrm{S}}$ was determined to be equal to $1170 \mathrm{~K} \cdot \mathrm{W}^{-1}$ ensuring sufficient adiabatic conditions during the realization of the phase transition and thermometer calibration.

The entrance to the thermometer well is located in the gaseous nitrogen evaporated from the Dewar (Fig. 2). This prevents air from condensing in the well. The entrance to the well should always be placed below the top-end level of the Dewar. 
Fig. 5 Influence of the temperature of the upper part of the thermometric well $\left(T_{2}\right)$ on the temperature observed at the triple point of argon
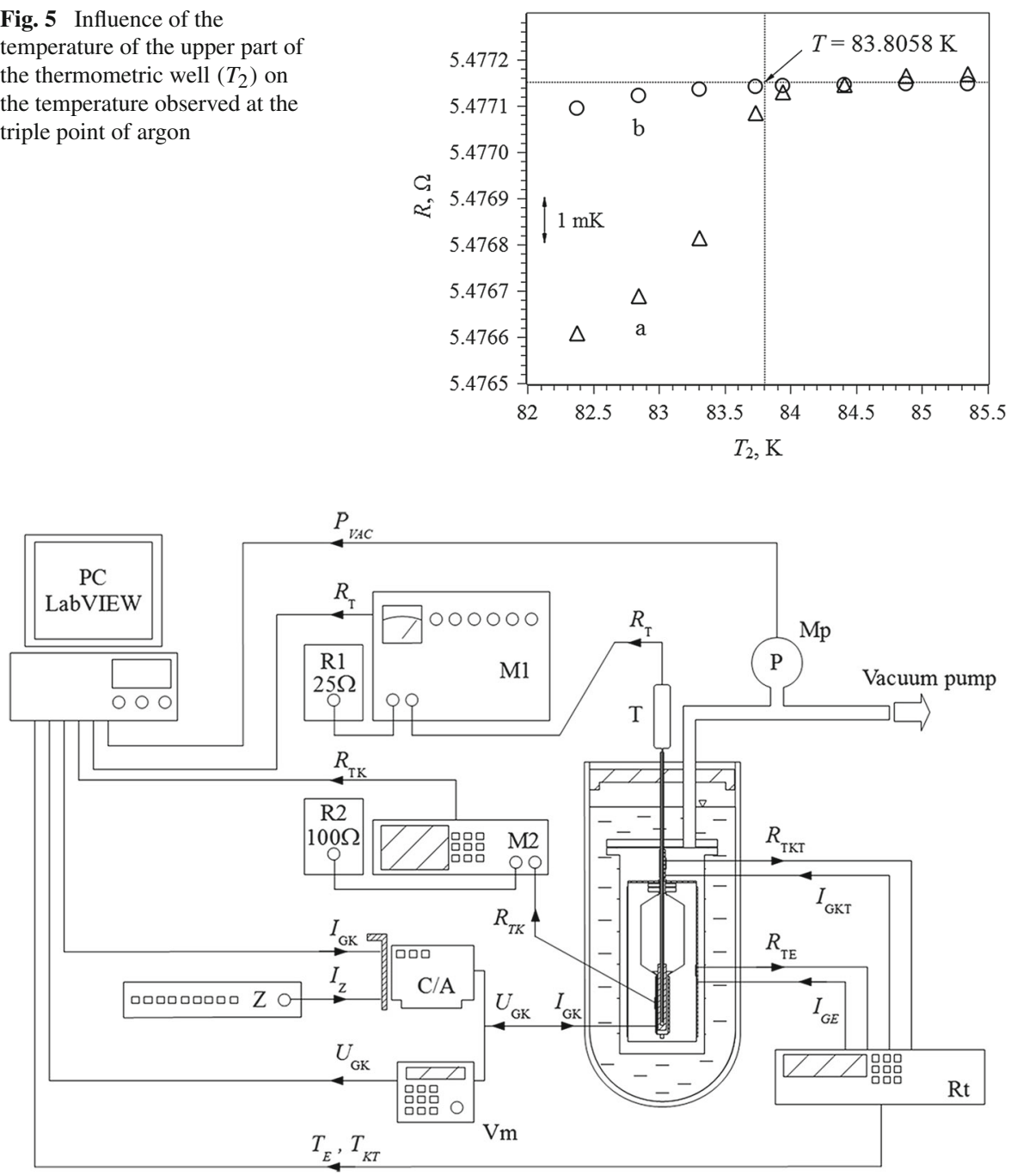

Fig. 6 Measuring system design: M1, M2 —-thermometer resistance bridges, Z-current supply, Vmvoltmeter, Rt-PID temperature controller, $\mathrm{T}$-long stem thermometer, $\mathrm{Mp}$ - vacuum meter

\subsection{Measuring System}

The measuring system is schematically shown in Fig. 6. The SPRT resistance is measured with a thermometric resistance bridge, M1, ensuring a measurement accuracy of $0.1 \mathrm{ppm}$. For monitoring the cell temperature, thermometer PRT1 is used. Its resistance is measured with another resistance bridge, M2 (accuracy of $1 \mathrm{ppm}$ ). The heater, $\mathrm{H} 1$, mounted on the cell is supplied by a current source (Advantech C/A 1723). A multimeter Vm measures the voltage on the heater (four-wire technique is used). The thermal shield is controlled with a PID controller with a nominal resolution of $1 \mathrm{mK}$. 
Fig. 7 Argon melting plateaux measured with the continuous heat method. $P$-cell heater power

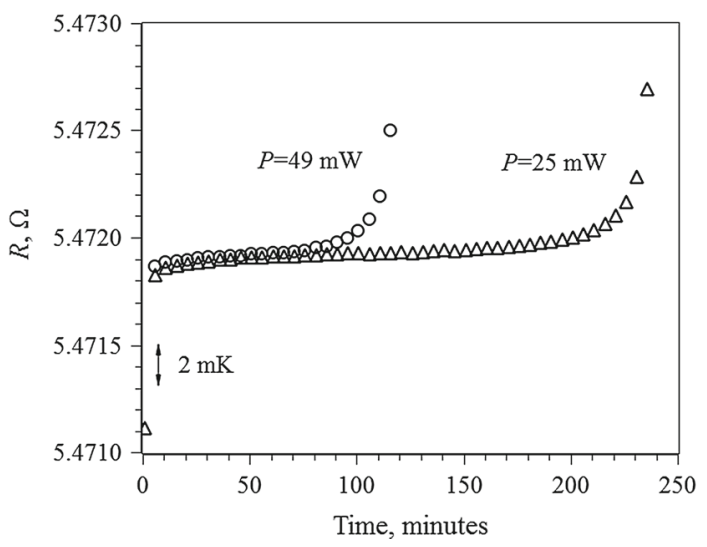

The thermal gradient on the shield was measured with two calibrated PRTs attached to the bottom and to the top part of the shield. The maximum temperature difference between the temperature on different parts of the screen was $50 \mathrm{mK}$.

The process of the argon triple-point realization is controlled by a LabVIEW computer program. The program lets the operator observe and control the thermal conditions in the cryostat and measure the temperatures of the cell (PRT1), the thermal shield (PRT2), and the thermometer well (PRT3). The SPRT resistance is measured automatically as well. The reading noise level of the SPRT resistance measurements was equivalent to $32 \mu \mathrm{K}$ when the thermometer current was $1 \mathrm{~mA}$. The observed self-heating of the SPRT was $1 \mathrm{mK}$ : all SPRT resistance values were corrected to zero current.

\section{Results}

The triple point of argon in this system was realized using both the continuous and pulse heating methods. In Fig. 7, the shape of the melting plateaux achieved during continuous heating of the cell is presented for two power values $-49 \mathrm{~mW}$ and $25 \mathrm{~mW}$. The determined heat of transition $Q$ was $380 \mathrm{~J}$. The discrepancy between the measured heat of transition and the expected one based on the quantity of enclosed substance was about $35 \mathrm{~J}$. Also, the thermal resistance $R_{\mathrm{CS}}$ for $F \approx 50 \%$ (where $F$ is the percentage of the molten argon) between the solid argon and a wall of the cell was estimated using the heat pulse method [12]. The temperature inside the cell before and after the heat pulse was measured. The thermal resistance value $R_{\mathrm{CS}}$ was calculated with

$$
R_{\mathrm{CS}}=\frac{\Delta T_{\mathrm{CS}}}{P_{\mathrm{PAS}}},
$$

where $\Delta T_{\mathrm{CS}}$ is the cell temperature difference before and after the heat pulse and $P_{\mathrm{PAS}}$ is the power of the heat pulse applied to the cell with cell heater H1. $R_{\mathrm{CS}}$ is about $0.02 \mathrm{~K} \cdot \mathrm{W}^{-1}$. Three argon melting curves determined using the heat pulse method are presented in Fig. 8a, b. These melting curves were obtained still without temperature control of the thermometer well. The transition width for $F$ between $20 \%$ and $80 \%$ is 
Fig. 8 (a) Argon melting curves measured with the heat pulse method as a function of $F$ and (b) argon melting curves measured with the heat pulse method as a function of $1 / F$
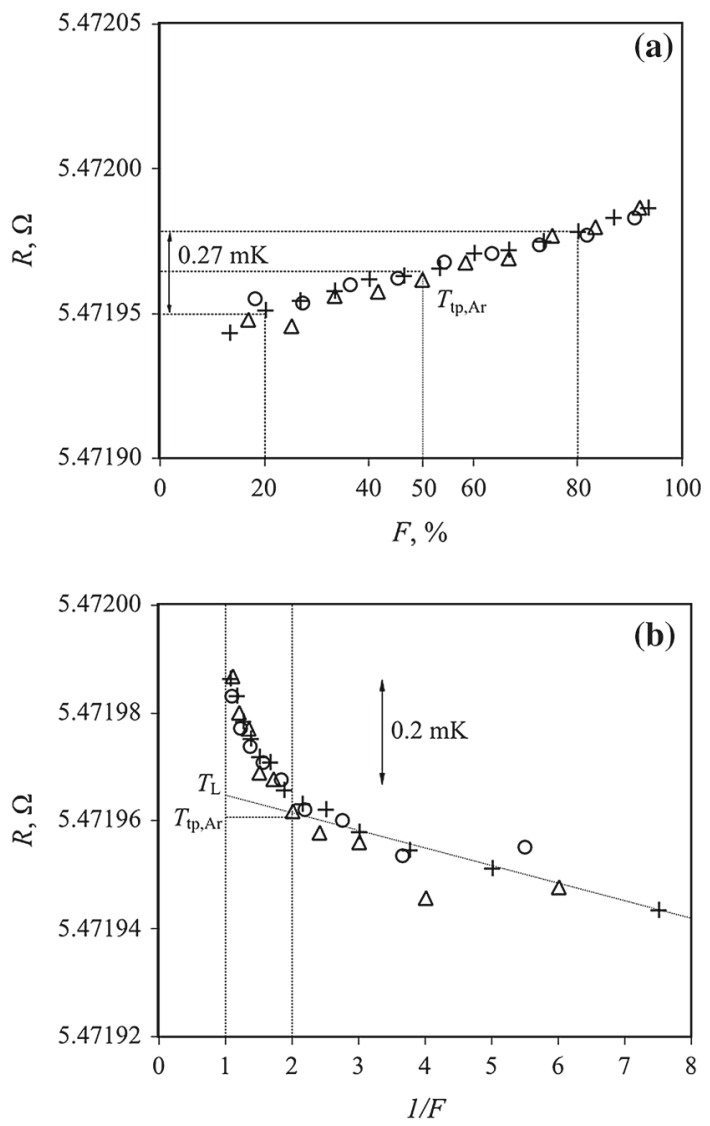

$<0.3 \mathrm{mK}$, and the reproducibility of the argon triple-point temperature for $F \approx 50 \%$ is better than $40 \mu \mathrm{K}$. Figure $8 \mathrm{~b}$ shows the melting curves as a function $R=f(1 / F)$. For the purpose of SPRT calibrations, the value at $F=50 \%$ is taken as $T_{\text {tp, Ar }}$ (argon triple-point temperature): the difference with respect to the true liquidus point $T_{\mathrm{L}}$ (a temperature at $1 / F=1$, extrapolated from the range $2 \leq 1 / F \leq 8$ ) is less than $50 \mu \mathrm{K}$.

The expanded uncertainty of the SPRT calibration is better then $0.3 \mathrm{mK}$ for $k=2$. The uncertainty budget of the SPRT calibration is presented in Table 1. The most significant uncertainty budget components described below are determination of the plateau value, propagation of the TPW uncertainty, and perturbing heat exchange effect. These three components determine over $90 \%$ of the total standard uncertainty of the SPRT calibration in the argon cell.

\subsection{Determination of the Plateau Value}

The value is estimated for $F=50 \%$. The uncertainty is evaluated from the melting range in the interval $F=20 \%$ to $80 \%$ assuming a rectangular distribution. The value of this uncertainty component was estimated from the results shown in Fig. 8a 
Table 1 Uncertainty budget for the calibration of long-stem SPRTs at the triple point of argon

Uncertainty component

Standard uncertainty $(\mathrm{mK})$

Chemical impurity

From the producers certificate-using the first cryoscopic constant [13]

Determination of the plateau value

The value is estimated for $F=50 \%$. The uncertainty is evaluated from the melting range in the interval $F=20 \%$ to $80 \%$ assuming a rectangular distribution. Value of this uncertainty component was estimated from the results shown in Fig. $8 \mathrm{a}(\Delta T=270 \mu \mathrm{K})$ assuming a symmetric, rectangular probability distribution

\section{Plateau repeatability}

The value is estimated for $F=50 \%$. The uncertainty evaluation is from the difference between the maximum and minimum value assuming a normal distribution

Perturbing heat exchange

The uncertainty evaluation is from the difference between value of temperature at the bottom of the thermometer well and $5 \mathrm{~cm}$ above the bottom, for $F=50 \%$ assuming a symmetric, rectangular probability distribution

\section{Hydrostatic head correction}

The value of this component is an estimation of the uncertainty of the distance between the argon level in the cell and the middle point of the sensor

Propagation from TPW uncertainty

Self-heating

Bridge measurement

Bridge uncertainty for SPRT $25 \Omega$

Standard resistor

Resistor uncertainty and temperature coefficient

Standard uncertainty

Expanded uncertainty

$(\Delta T=270 \mu \mathrm{K})$ assuming a symmetric, rectangular probability distribution using

$$
u_{1}\left(T_{\mathrm{tpAr}}\right)=\frac{\Delta T}{2 \sqrt{3}}
$$

\subsection{Propagation of the TPW Uncertainty}

The uncertainty of the long-stem SPRT calibration in the TPW $u\left(T_{\mathrm{TPW}}\right)$ is $<280 \mu \mathrm{K}$. The ratio $R\left(T_{\mathrm{tpAr}}\right) / R(\mathrm{TPW})$ is 0.22 . The propagation of the TPW uncertainty component value $u_{2}\left(T_{\mathrm{tpAr}}\right)$ is determined from

$$
u_{2}\left(T_{\mathrm{tpAr}}\right)=u\left(T_{\mathrm{TPW}}\right) \cdot \frac{R\left(T_{\mathrm{tpAr}}\right)}{R(\mathrm{TPW})}
$$




\subsection{Perturbing Heat Exchange}

The heat exchange between the cell and the external environment during the realization of the triple point can affect the measurement. The influence of this effect can be estimated by measuring the immersion profile in the thermometer well in the cell. The difference $\Delta T_{+5}$ between the value of the temperature at the bottom of the thermometer well and $5 \mathrm{~cm}$ above the bottom for $F=50 \%$ is $<150 \mu \mathrm{K}$. The uncertainty component value, assuming a symmetric rectangular probability distribution is determined using

$$
u_{3}\left(T_{\mathrm{tpAr}}\right)=\frac{\Delta T_{+5}}{2 \sqrt{3}}
$$

Small as for the long-stem thermometer, the uncertainty value of the perturbing heat exchange is achieved by the use of heater H3 (Fig. 2). The heater cooperating with the PRT3 thermometer and temperature controller Rt is a compensating heat flux along the thermometer well.

\section{Conclusion}

A new cryostat for the calibration of long-stem SPRTs at the argon triple point in quasi-adiabatic conditions was tested using continuous and pulse heating methods. The results obtained show that the reproducibility of the phase transition is about $40 \mu \mathrm{K}$. The expanded uncertainty of the SPRT calibration is better then $0.3 \mathrm{mK}$. The discrepancy between the measured heat of transition and the expected one based on the quantity of enclosed substance is still under investigation.

Acknowledgment The presented work was done under the project of the National Center of Research and Development (Poland) No. PBS1/A9/6/2012 (ID:179275).

Open Access This article is distributed under the terms of the Creative Commons Attribution License which permits any use, distribution, and reproduction in any medium, provided the original author(s) and the source are credited.

\section{References}

1. J. Ancsin, J.M. Phillips, Rev. Sci. Instrum. 55, 1321 (1984)

2. G. Furukawa, in Temperature: Its Measurement and Control, in Science and Industry, vol. 6, ed. by J.F. Schooley (AIP, New York, 1992), pp. 265-269

3. I. Yang, C.H. Song, K.H. Kang, Y.G. Kim, K.S. Gam, Int. J. Thermophys. 29, 1740 (2008)

4. R. Ding, M. Zhao, E. Nerdrum, D. Meier, Int. J. Thermophys. 32, 2252 (2011)

5. M. Dobre, I. Didialaoui, Y. Hermier, Int. J. Thermophys. 32, 1573 (2011)

6. I. Didi-Alaoui, D. Fiorillo, A. Vergé, F. Sparasci, D. Jouin, Y. Hermier, in Proceedings of Ninth International Temperature Symposium (Los Angeles), Temperature: Its Measurement and Control, in Science and Industry, vol. 8, ed. by C.W. Meyer, A.I.P. Conference Proceedings 1552 (AIP, Melville, NY, 2013), pp. 474-479

7. F. Pavese, J. Ancsin, D.N. Astrov, J. Bonhoure, G. Bonnier, G.T. Furukawa, R.C. Kemp, H. Maas, R.L. Rusby, H. Sakurai, L. Shan-Kang, Metrologia 20, 127 (1984)

8. A.G. Steele, B. Fellmuth, D.I. Head, Y. Hermier, K.H. Kang, P.P.M. Steur, W.L. Tew, Metrologia 39, 551 (2002) 
9. F. Pavese, D. Ferri, I. Peroni, A. Pugliese, P.P.M. Steur, B. Fellmuth, D. Head, L. Lipiński, A. Peruzzi, A. Szmyrka-Grzebyk, L. Wolber, in Temperature: Its Measurement and Control, in Science and Industry, vol. 7, ed. by D.C. Ripple (AIP, New York, 2003), pp. 173-178

10. B. Fellmuth, L. Wolber, D.I. Head, Y. Hermier, K.D. Hill, T. Nakano, F. Pavese, A. Peruzzi, R.L. Rusby, V. Shkraba, A.G. Steele, P.P.M. Steur, A. Szmyrka-Grzebyk, W.L. Tew, L. Wang, D.R. White, Metrologia 49, 257 (2012)

11. F. Pavese, G. Molinar, Modern Gas-Based Temperature and Pressure Measurements, 2nd edn. (Springer, New York, 2013), p. 110

12. F. Pavese, G. Molinar, Modern Gas-Based Temperature and Pressure Measurements, 2nd edn. (Springer, New York, 2013), pp. 80-81

13. F. Pavese, Metrologia 48, 268 (2011) 